\title{
Rearview
}

\section{Degrees of separation: the case of BT}

\author{
A regular column on the information industries
}

\author{
Jason Whalley and Peter Curwen
}

Jason Whalley is based at the Newcastle Business School, Northumbria University, Newcastle upon Tyne, Tyne and Wear, UK. Peter Curwen is Professor at the Newcastle Business School, Northumbria University, Newcastle upon Tyne, UK.
The socio-economic benefits of broadband are widely acknowledged. Governments around the world have adopted a range of strategies to ensure that broadband networks are available across their territories. Some have thrown large amounts of money at the issue, subsidising the rollout of broadband networks or even building their own when they became frustrated at the pace of private sector developments, while others have encouraged smaller scale initiatives such as community based networks. Within the UK, a different approach was adopted: functional - that is, operational separation and the creation of Openreach.

Created in 2005 when functional separation was imposed on BT, Openreach provides the infrastructure on which most customers and businesses within the UK rely for their broadband services. Openreach is arguably a "regulatory experiment" - only a handful of other countries have implemented functional separation, and no other country has exactly replicated the model adopted by the UK. However, virtually since the day it was created, Openreach has been subject to wide-ranging criticism, leading some to question whether functional separation could deliver the sort of network that the UK needs in the coming years.

During 2016/2017, this criticism became increasingly vocal. In particular, Openreach was criticised for the poor quality of the services that it delivered and its cautious attitude towards infrastructure investment that perpetuated the role of copper used within its network a strategy that, unsurprisingly, has been very profitable for BT. Although the combination of fibre-to-the-cabinet and copper, which is currently being improved further through the deployment of so-called "g.fast" technologies, has provided the UK with superficially attractive broadband speeds, the average downlink disguises wildly varying delivery speeds according to location and even "not-spots". Openreach has continued to be criticised by its rivals like Talk Talk, Sky and Vodafone as well as by politicians. There is a concern that the company is investing too little in its infrastructure and that the continued use of copper in the network will eventually result in the UK being left behind by other EU countries which are instead focusing on a "full fibre" future. In early 2016, Ofcom, the regulator, published its initial conclusions from the Strategic Review of Digital Communications that it had initiated 
the previous year. These contained a ten-year vision for communication services in the UK and a strategy to achieve it. At the heart of this vision and strategy was Openreach.

Ofcom highlighted the need for all operators in the telecommunications industry, Openreach included, to improve the quality of their services. It also stated that the independence of Openreach should be increased so that it could better respond to the needs of its customers. Various mechanisms to strengthen this independence were suggested, including greater control over its budget, strategy and decision-making as well as amending how Openreach was governed so that it became more independent of BT. Significantly, while noting that the status quo was unacceptable, Ofcom took the option of structural separation forcing BT to divest Openreach - off the table, although it did reserve the right to return to this issue if improvements could not be achieved.

More details about how the governance of Openreach would be reformed were published by Ofcom in July 2016. Ofcom confirmed its approach, describing its preferred option of strengthening the independence of Openreach as "legal separation" - Openreach would become a wholly owned subsidiary of BT, with its own board and no direct lines of reporting between Openreach and BT executives. Openreach would also own the assets that it controlled, with its employees working for itself and not BT and, to help create a sense of independence from BT, Openreach would also have its own brand. Finally, Ofcom noted that it was developing detailed proposals for discussion with the European Commission later on in 2016.

Some companies, such as Sky and CK Hutchison (which trades as "3" in the UK), were disappointed by Ofcom's announcement, and just a day later, the "Fix Britain's Internet" campaign was launched, supported by Sky, Talk Talk, Vodafone and the Federation of Communication Services, to lobby for change and encourage individuals to complain to their Member of Parliament. It even provided those who wished to complain with an email template that called on Sharon White, the CEO of Ofcom, to impose structural separation on BT. Pressure on BT continued to mount when, in August, a former minister suggested that BT should be split up and the CEOs of Sky, Talk Talk and Vodafone jointly attacked BT's failure to invest in fibre. In reply, BT highlighted the track record of Openreach and joined with Virgin Media, the only operator with an extensive broadband cable network, to state that between them they had invested £15bn in their networks over the previous five years. It promised to invest £6bn over the course of the next three years and to strengthen Openreach's governance through appointing an independent board. Openreach would also gain greater control over its budget.

Notwithstanding this offer, rumours began to emerge that an impasse had been reached between BT and Ofcom. One issue that was proving particularly problematic was the pension scheme or, more accurately, its deficit. There are roughly 300,000 BT pensioners plus a further 37,000 employees currently accruing benefits and according to a number of interested parties - but by no means all of them - their pensions lie at the heart of what can sensibly be achieved. Throughout the current decade, the BT pension fund has been in deficit - a mere $£ 2 b n$ at its lowest point but collapsing to £12bn in 2015-2016 where, give or take, it currently remains according to UBS. BT is committed in principle to wiping out the deficit by 2030 at the rate of $£ 500-700 m$ per annum, but all of these numbers relate to a unitary organization. In practice, some two-thirds of the deficit belongs to Openreach and BT, its unions and its pension trustees argue that a separation would affect the Crown Guarantee that was part of the 1984 privatisation which stated that all promised pensions would be underwritten by taxpayers. To recreate this for an independent Openreach would require an Act of Parliament or alternatively some kind of hugely expensive insurance policy.

The impasse was broken by Ofcom when, in late November 2016, it announced that it would start a formal notification process that would require the "legal separation" of Openreach from BT. Ofcom clearly felt that the proposals volunteered by BT were unsatisfactory. The announcement also alluded to the divergent views on the impact of changes to Openreach of the pension scheme, but while an accompanying note laid out Ofcom's initial thoughts on the relationship, it arguably raised more questions than answers. Given this uncertainty, it was safe to say that the pension scheme would continue to play a role in any discussion of Openreach's future.

Support for BT came from Deutsche Telekom, which was not surprising, given that it had owned a 12 per cent stake in BT since it sold its half-share in EE to BT in 2015. In addition to arguing that legal separation would not work, Deutsche Telekom suggested that imposing this on BT would make the UK as a whole less attractive to foreign investors. There was also some speculation that other European incumbents would support BT in arguing against legal 
separation out of fear that a similar policy would be adopted in their home markets. This is somewhat surprising, given that functional separation has not been widely copied in Europe, but they may be motivated by the fact that it is now available as a regulatory tool across the European Union.

While Ofcom stated that it would notify the European Commission of its plans, it intriguingly noted that it remained open to any proposals that BT would make to address its concerns. As a consequence, some commentators suggested that the notification was intended to pile pressure on BT to improve its voluntary proposals. As such, the formal notification marked yet another stage in the seemingly endless saga of Openreach and the quality of Britain's broadband infrastructure. The move from functional to legal separation also marked a switch from one regulatory experiment to another, with the almost certain consequence that in the fairly near future the UK would be discussing whether legal separation was appropriate and, if it was not, what to do next.

In February 2017, BT named the first members of the independent board being set up for Openreach but Ofcom promptly responded that this did not amount to "legal separation". Nevertheless, this was officially declared to be in place in mid-March when BT announced that it was transferring 32,000 engineers to Openreach which would lose its BT branding and be obliged to make investment decisions in the interests of all of its customers. However, BT would remain the outright owner of Openreach, control its budget and have the right to veto the appointment of a CEO for Openreach who would report directly to BT on financial matters. In other words, as one analyst noted, BT had not given much away in terms of control though another suggested that the need for Openreach to consult its rivals and to show its independence could result in its investment shifting towards fibre.

Ultimately, the issue of needing to transfer a massive pension deficit to a wholly independent Openreach meant that it had to remain part of BT - and the share price promptly increased. BT has not been obliged to increase its investment beyond the (inadequate) sums already on the table, and Ofcom has yet to explain how it will guarantee that all of Openreach's customers will be treated equally. If this explanation is unconvincing or the mechanisms suggested do not reassure BT's rivals regarding how they will be treated, then legal separation will not resolve the debate but instead will be a temporary pause in hostilities between BT, its rivals and Ofcom.

\section{Corresponding author}

Peter Curwen can be contacted at: pjcurwen@hotmail.com 